\title{
Matrix Based Fuzzy Clustering for Categorization of Web Users and Web Pages
}

\author{
G. Sudhamathy, \\ Department of Computer Applications, \\ Velammal College Of Engineering and Technology, \\ Madurai 625 009, India
}

\author{
C. Jothi Venkateswaran, \\ Department of Computer Science, \\ Presidency College (Autonomous), \\ Chennai 600 005, India
}

\begin{abstract}
Categorization of Web Users and Web Pages are the fundamental tasks of Web Personalization. In this paper it is proposed a Matrix Based Fuzzy Clustering Approach MBFCA and experimentally evaluated the approach for the effective discovery of web user clusters and web page clusters. The use of MBFCA enables the generation of clusters that can capture the Web user's navigation behavior based on their interest. In web usage analysis, many a times there are no sharp boundary between clusters. Hence fuzzy clustering is better suited for Web Usage Mining. Experimental results presented, the clusters generated by applying MBFCA, are intended to be used to make recommendations by suggesting interesting links to the user.
\end{abstract}

\section{General Terms}

Pattern Recognition, Algorithm.

\section{Keywords}

Web Usage Mining, Web Logs Clustering, Web Personalization, Fuzzy Logic, Matrix Based Fuzzy Clustering.

\section{INTRODUCTION}

Web usage mining is a very important part of web mining, and it tries to discover interesting web user access patterns or knowledge from the web $\log$ records [1]. Web log files contain a huge amount of data about user access patterns. Hence, if properly exploited, they can reveal useful information about the browsing behavior of users in a site. Analyzing and exploring regularities in web log records can identify customers for e-commerce, enhance quality of IIS and improve web server system performance [7].

Web usage mining approach applies Data Mining algorithms on Web usage data and among them clustering is an effective way to group users with common browsing behavior [8]. In the choice of the clustering method for Web usage mining, one important constraint to be considered is the possibility to obtain overlapping clusters, so that a user can belong to more than one group [9]. To deal with the ambiguity and the uncertainty underlying Web interaction data, as well as to derive overlapping clustering, fuzzy clustering appears to be an effective tool. Web mining has obvious fuzzy characteristic, so fuzzy clustering is better suited for the web mining [2]. So the concept of Matrix Based Fuzzy Clustering Approach MBFCA is put forward for Web usage mining.

\section{PROPOSED APPROACH}

The input data object of the Matrix Based Fuzzy Clustering is the web source matrix which represents the data objects and its attributes of the given web data set. But the processing data object of MBFCA is web fuzzy similarity matrix using which the web users and web pages clustering is done. So it is required to abstract web source data firstly and then transform it into web fuzzy matrix which is suitable for fuzzy clustering [3]. In the end, fuzzy clustering method is applied on web fuzzy matrix to obtain the clustering results. The Matrix Based Fuzzy Clustering Approach (MBFCA) is shown in Figure 1.

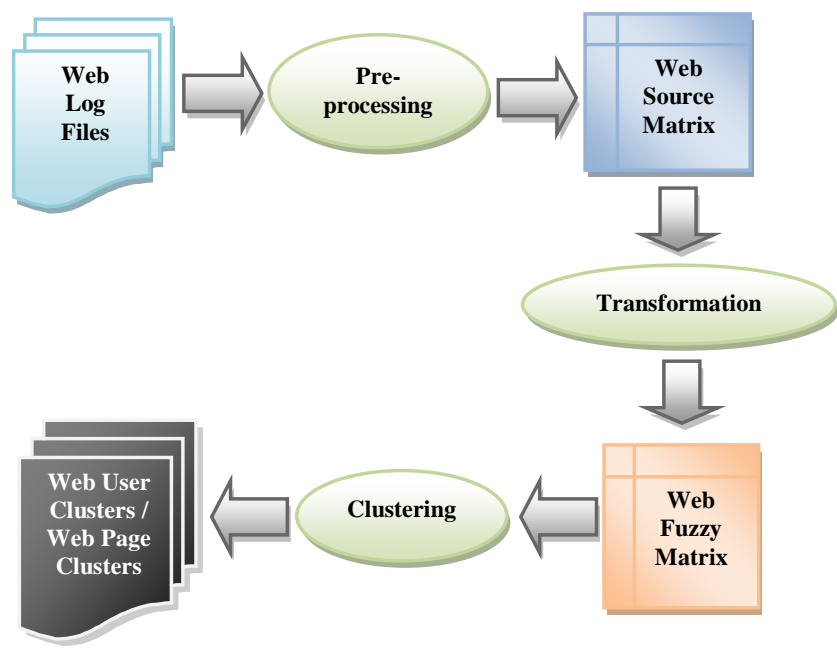

Fig 1: Matrix Based Fuzzy Clustering Approach

\section{PRE-PROCESSING}

Web log files from the web server are extracted and parsed. That is the delimited fields in the web log text files are separated and we are interested in the fields date, time, Client IP address, URL Visited and User Agent. After this the resultant data is cleaned by removing the unwanted requests and by removing all requests that have .JPEG, .GIF and .CSS files in the URL Visited field.

The next step in pre-processing is user identification [10]. The $\log$ entries in the web $\log$ files are chronologically ordered based on the different user's requests from their client machine to the web server. Hence the data records for each month (or any specific period range) are split.

From each month data identify different users[11]. One user is the request from a single Client IP address and User Agent field where the duration between two consecutive requests from the same Client IP address and User Agent does not exceed the idle time of 30 minutes. Based on this assumption, the records for each month is processed and the records with aggregated fields, From_Date, To_Date, User_Id, Page_Id, 
Visit_Frequency are obtained. The visit_frequency field has the count of the number of times the particular user visits the particular page. This is done and obtained for all months (periods), for all users and for all pages. Note, the period specification is optional to the user. That is the user can decide whether it is a Month or a Week, or Quarter or Semester or Year.

There is another type of data that is required out of this preprocessing step is that the number of common pages accessed by any set of users and the number of common users accessing any set of pages. This is also obtained by analyzing and aggregating the base data that is got after parsing and cleaning the web log files.

So, as a result of the pre-processing step, there are four types of web source matrix as listed below [4]. Let $n$ be the total number of users and $\mathrm{m}$ be the total number of pages in a period.

1. Web source matrix for representing the visit frequency of each web user on each web page. This matrix is of the form up $_{\mathrm{ij}}$ where $(\mathrm{i}=1,2, \ldots \mathrm{n} ; \mathrm{j}=1,2, \ldots \mathrm{m})$

2. Web source matrix for representing the visit frequency of each web page by each web user. This matrix is of the form $\mathrm{pu}_{\mathrm{ij}}$ where $(\mathrm{i}=1,2, \ldots \mathrm{m} ; \mathrm{j}=1,2, \ldots \mathrm{n})$.

3. Web source matrix for representing the common number of pages visited by each pair of web site users. This matrix is of the form $u_{i j}$ where $(i=1,2, \ldots n ; j=1,2, \ldots n)$.

4. Web source matrix for representing the common number of users visiting every pair of web sites. This matrix is of the form $\mathrm{pp}_{\mathrm{ij}}$ where $(\mathrm{i}=1,2, \ldots \mathrm{m} ; \mathrm{j}=1,2, \ldots \mathrm{m})$.

\section{TRANSFORMATION}

A web source matrix of the form $R=\left(r_{i j}\right) n x m$ can be converted into a web fuzzy matrix $R^{\prime}=\left(r_{i j}\right) n \times n$ where every $r_{i j} \in[0,1]$. This conversion is done by applying the transformation step. That is by applying the below formula on the web source matrix the web fuzzy matrix is obtained.

$$
\mathrm{r}_{\mathrm{ij}}=1-c \sum_{k=1}^{m}\left|\mathrm{x}_{\mathrm{ik}}-\mathrm{x}_{\mathrm{jk}}\right|
$$

The $\mathrm{c}$ in the formula is the factor that is selected to make the $\mathrm{r}_{\mathrm{ij}}$ in the range of $[0,1]$ and it can be adjusted according to the practical situation.

\section{CLUSTERING}

The next step is performing the clustering of the web users and web pages. Under Web User Clustering there is Clustering based on the Relative Active Degree of the Web Users and Clustering based on the Correlative Degree of the Web Users. Similarly, under Web Page Clustering, there is Clustering based on the Relative Interestingness Degree of the Web Pages and there is Clustering based on the Correlative Degree of the Web Pages [5].

The Clusters under the category Relative Active Degree of the Web Users are named as Most Active Users, More Active Users, Active Users and Inactive Users. The Clusters under the category Correlative Degree of the Web Users are named as Most Firm Relation Users, More Firm Relation Users, Firm Relation Users and In Firm Relation Users.
The Clusters under the category Relative Interestingness Degree of the Web Pages are named as Most Interesting Pages, More Interesting Pages, Interesting Pages and Uninteresting Pages. The Clusters under the category Correlative Degree of the Web Pages are named as Most Firm Relation Pages, More Firm Relation Pages, Firm Relation Pages and In Firm Relation Pages.

For this clustering, sort the elements $r_{i j}(i=1, \ldots, n ; j=1, \ldots, m)$ that are different from each other in the web fuzzy matrix R' in the descending order of values and form a number list of the form $\mathrm{L}\left(1=\mathrm{C}_{1}>\mathrm{C}_{2}>\ldots>\mathrm{C}_{\mathrm{m}}\right)$ and let the factor $\mathrm{C}$ search the number list $\mathrm{L}$.

Of these elements of the number list $\mathrm{L}$ ignore the highest value $C_{1}=1$. When evaluating $C_{2}$, put $x_{i}$ and $x_{j}$ into one cluster if $r_{i j}=C_{2}$. When evaluating $C_{3}$, put $x_{i}$ and $x_{j}$ into one cluster if $r_{i j}=C_{3}$. Combine this cluster with the existing clusters formed by the previous steps if there is any common element in both these clusters. This step is repeated until all the web objects are in one cluster [6].

\section{APPLICATION AND RESULTS}

Web access log data from a website of a university is taken to verify the results. Some web pages are selected from the result of the pre-processing step and made an abstract of the web page set and web users set as $P=\left\{p_{1}, p_{2}, p_{3}, p_{4}, p_{5}, p_{6}, p_{7}, p_{8}\right.$, $\left.\mathrm{p}_{9}\right\} \& \mathrm{U}=\left\{\mathrm{u}_{1}, \mathrm{u}_{2}, \mathrm{u}_{3}, \mathrm{u}_{4}, \mathrm{u}_{5}\right\}$.

\subsection{Web User Clustering}

\subsubsection{Relative Active Degree of Web Users}

From the pre-processed data the total number of times each web user accessing each web page; $\mathrm{up}_{\mathrm{ij}}$ where $(i=1, \ldots, 5 ; \mathrm{j}=$ $1, \ldots, 9)$ is obtained.

From Table 1. the original web source matrix $\mathrm{R}$ is got. Web fuzzy matrix R' is obtained after applying the transformation on the web source matrix using the above mentioned formula. In the formula the factor $\mathrm{c}$ is assumed to be 0.01 .

Table 1. Source Data.

\begin{tabular}{|c|c|c|c|c|c|c|c|c|c|}
\hline & p1 & p2 & $\mathbf{p 3}$ & $\mathbf{p 4}$ & $\mathbf{p 5}$ & $\mathbf{p 6}$ & $\mathbf{p 7}$ & $\mathbf{p 8}$ & $\mathbf{p 9}$ \\
\hline $\mathbf{u 1}$ & 32 & 23 & 9 & 15 & 14 & 26 & 10 & 18 & 21 \\
\hline $\mathbf{u 2}$ & 15 & 28 & 23 & 23 & 21 & 23 & 25 & 34 & 30 \\
\hline $\mathbf{u 3}$ & 11 & 21 & 19 & 11 & 18 & 12 & 30 & 24 & 18 \\
\hline $\mathbf{u 4}$ & 18 & 21 & 18 & 9 & 17 & 23 & 18 & 15 & 14 \\
\hline $\mathbf{u 5}$ & 17 & 27 & 24 & 10 & 16 & 34 & 14 & 16 & 23 \\
\hline
\end{tabular}

$$
\mathrm{r}_{\mathrm{ij}}=1-0.01 \sum_{k=1}^{m}\left|\mathrm{x}_{\mathrm{ik}}-\mathrm{x}_{\mathrm{jk}}\right|
$$

$$
R=\left[\begin{array}{lllllllll}
32 & 23 & 09 & 15 & 14 & 26 & 10 & 18 & 21 \\
15 & 28 & 23 & 23 & 21 & 23 & 25 & 34 & 30 \\
11 & 21 & 19 & 11 & 18 & 12 & 30 & 24 & 18 \\
18 & 21 & 18 & 09 & 17 & 23 & 18 & 15 & 14 \\
17 & 27 & 24 & 10 & 16 & 34 & 14 & 16 & 23
\end{array}\right]
$$

$$
R^{\prime}=\left[\begin{array}{lllll}
1.00 & 0.06 & 0.16 & 0.45 & 0.43 \\
0.06 & 1.00 & 0.32 & 0.25 & 0.33 \\
0.16 & 0.32 & 1.00 & 0.53 & 0.29 \\
0.45 & 0.25 & 0.53 & 1.00 & 0.60 \\
0.43 & 0.33 & 0.29 & 0.60 & 1.00
\end{array}\right]
$$

After this, clustering step is applied to get the web user clusters based on the relative active degree of the web users. 
Form the descending degree of the values in the web fuzzy matrix. The values are: $1>0.6>0.53>0.45>0.43>0.33$.

When the value is 1 the web users set $U$ is clustered into five clusters: $\left\{\left\{u_{1}\right\},\left\{u_{2}\right\},\left\{u_{3}\right\},\left\{u_{4}\right\},\left\{u_{5}\right\}\right\}$. The result has no distinct meaning here.

When the value is 0.6 , it corresponds to the users $\mathrm{u}_{4}$ and $\mathrm{u}_{5}$. Hence cluster $u_{4}$ and $u_{5}$ together. Now the user clusters are: $\left\{\left\{\mathrm{u}_{1}\right\},\left\{\mathrm{u}_{2}\right\},\left\{\mathrm{u}_{3}\right\},\left\{\mathrm{u}_{4}, \mathrm{u}_{5}\right\}\right\}$. The result shows that web users' $\mathrm{u}_{4}$ and $\mathrm{u}_{5}$ are the most active users and their related active degree is 0.6 .

When the value is 0.53 , it corresponds to the users $u_{3}$ and $u_{4}$. Hence cluster $u_{3}$ and $u_{4}$ together. Since $u_{4}$ is already in a cluster with $\mathrm{u}_{5}$, cluster $\mathrm{u}_{3}, \mathrm{u}_{4}$ and $\mathrm{u}_{5}$ together. Now the user clusters are: $\left\{\left\{u_{1}\right\},\{u 2\},\{u 3, u 4, u 5\}\right\}$. The result shows that web user $u_{3}$ is the more active user and the related active degree of $\mathrm{u}_{3}, \mathrm{u}_{4}$ and $\mathrm{u}_{5}$ is 0.53 .

When the value is 0.45 , it corresponds to the users $u_{1}$ and $u_{4}$. Hence cluster $u_{1}$ and $u_{4}$ together. Since $u_{4}$ is already in a cluster with $\mathrm{u}_{5}$ and $\mathrm{u}_{3}$, cluster $\mathrm{u}_{1}, \mathrm{u}_{3}, \mathrm{u}_{4}$ and $\mathrm{u}_{5}$ together. Now the user clusters are: $\left\{\left\{\mathrm{u}_{1}, \mathrm{u}_{3}, \mathrm{u}_{4}, \mathrm{u}_{5}\right\},\left\{\mathrm{u}_{2}\right\}\right\}$. The result shows that web user $u_{1}$ is the active user and the related active degree of $\mathrm{u}_{1}, \mathrm{u}_{3}, \mathrm{u}_{4}$ and $\mathrm{u}_{5}$ is 0.45 .

When the value is 0.43 , there will be no significant change in the clusters as it corresponds to the users $\mathrm{u}_{1}$ and $\mathrm{u}_{5}$ which are already included in the above cluster.

When the value is 0.33 , it corresponds to the users $\mathrm{u}_{2}$ and $\mathrm{u}_{5}$. Hence cluster $u_{2}$ and $u_{5}$ together. Since $u_{5}$ is already in a cluster with $\mathrm{u}_{1}, \mathrm{u}_{3}$ and $\mathrm{u}_{4}$, cluster $\mathrm{u}_{1}, \mathrm{u}_{2}, \mathrm{u}_{3}, \mathrm{u}_{4}$ and $\mathrm{u}_{5}$ together. Now the single user cluster is: $\left\{\left\{\mathrm{u}_{1}, \mathrm{u}_{2}, \mathrm{u}_{3}, \mathrm{u}_{4}, \mathrm{u}_{5}\right\}\right\}$. The result shows that web user $u_{2}$ is the inactive user and the related active degree of all the users is 0.33 .

Now stop clustering as all the users are in a single cluster.

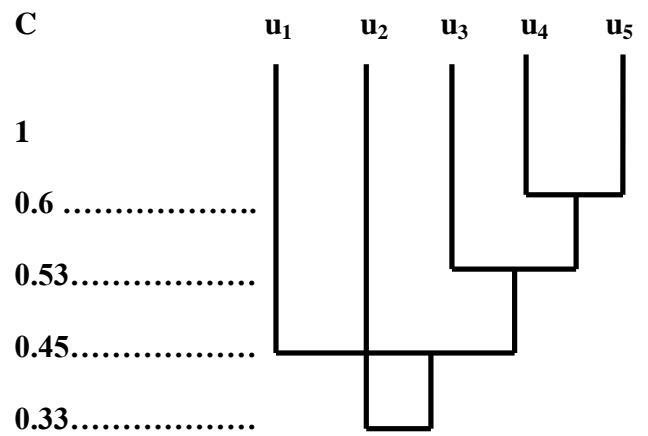

Fig 2: Resultant Graph1 of the user clusters

\subsubsection{Correlative Degree of Web Users}

From the pre-processed data the total number of common pages accessed by a set of web users; $\mathrm{uu}_{\mathrm{ij}}$ where $(\mathrm{i}=1, \ldots, 5 ; \mathrm{j}$ $=1, \ldots .5)$ is obtained.

Table 2. Source Data

\begin{tabular}{|c|c|c|c|c|c|}
\hline & $\mathbf{u 1}$ & $\mathbf{u 2}$ & $\mathbf{u 3}$ & $\mathbf{u 4}$ & $\mathbf{u 5}$ \\
\hline $\mathbf{u 1}$ & 5 & 3 & 6 & 1 & 4 \\
\hline $\mathbf{u 2}$ & 1 & 8 & 3 & 2 & 0 \\
\hline $\mathbf{u 3}$ & 2 & 7 & 9 & 4 & 3 \\
\hline $\mathbf{u 4}$ & 8 & 2 & 8 & 7 & 7 \\
\hline $\mathbf{u 5}$ & 1 & 5 & 4 & 3 & 2 \\
\hline
\end{tabular}

From Table 2, R and R' are got and the factor $\mathrm{c}$ in the transformation step is set to 0.02 .

$$
\begin{gathered}
\mathrm{r}_{\mathrm{ij}}=1-0.02 \sum_{k=1}^{m}\left|\mathrm{x}_{\mathrm{ik}}-\mathrm{x}_{\mathrm{jk}}\right| \\
R=\left[\begin{array}{lllll}
5 & 3 & 6 & 1 & 4 \\
1 & 8 & 3 & 2 & 0 \\
2 & 7 & 9 & 4 & 3 \\
8 & 2 & 8 & 7 & 7 \\
1 & 5 & 4 & 3 & 2
\end{array}\right] \\
R^{\prime}=\left[\begin{array}{llllll}
1.00 & 0.66 & 0.72 & 0.70 & 0.76 \\
0.66 & 1.00 & 0.74 & 0.40 & 0.88 \\
0.72 & 0.74 & 1.00 & 0.62 & 0.80 \\
0.70 & 0.40 & 0.62 & 1.00 & 0.54 \\
0.76 & 0.88 & 0.80 & 0.54 & 1.00
\end{array}\right]
\end{gathered}
$$

After this apply clustering step to get the web user clusters based on the correlative degree of the web users. Form the descending degree of the values in the web fuzzy matrix. The values are: $1>0.88>0.80>0.76>0.74>0.66>0.62>0.54$.

When the value 1 the web users set $U$ is clustered into five clusters: $\left\{\left\{\mathrm{u}_{1}\right\},\left\{\mathrm{u}_{2}\right\},\left\{\mathrm{u}_{3}\right\},\left\{\mathrm{u}_{4}\right\},\left\{\mathrm{u}_{5}\right\}\right\}$. The result has no distinct meaning here.

When the value is 0.88 , it corresponds to the users' $\mathrm{u}_{2}$ and $\mathrm{u}_{5}$. Hence cluster $\mathrm{u}_{2}$ and $\mathrm{u}_{5}$ together. Now the user clusters are: $\left\{\left\{\mathrm{u}_{1}\right\},\left\{\mathrm{u}_{3}\right\},\left\{\mathrm{u}_{4}\right\},\left\{\mathrm{u}_{2}, \mathrm{u}_{5}\right\}\right\}$. The result shows that web users' $\mathrm{u}_{2}$ and $\mathrm{u}_{5}$ are the most firm relation users and their correlative degree is 0.88 .

When the value is 0.80 , it corresponds to the users' $u_{3}$ and $u_{5}$. Hence cluster $u_{3}$ and $u_{5}$ together. Since $u_{5}$ is already in a cluster with $\mathrm{u}_{2}$, cluster $\mathrm{u}_{2}, \mathrm{u}_{3}$ and $\mathrm{u}_{5}$ together. Now the user clusters are: $\left\{\left\{\mathrm{u}_{1}\right\},\left\{\mathrm{u}_{4}\right\},\left\{\mathrm{u}_{2}, \mathrm{u}_{3}, \mathrm{u}_{5}\right\}\right\}$. The result shows that web user $u_{3}$ is the more firm relation user and the related correlative degree of $\mathrm{u}_{2}, \mathrm{u}_{3}$ and $\mathrm{u}_{5}$ is 0.80 .

When the value is 0.76 , it corresponds to the users' $u_{1}$ and $u_{5}$. Hence cluster $u_{1}$ and $u_{5}$ together. Since $u_{5}$ is already in a cluster with $\mathrm{u}_{2}$ and $\mathrm{u}_{3}$, cluster $\mathrm{u}_{1}, \mathrm{u}_{2}, \mathrm{u}_{3}$ and $\mathrm{u}_{5}$ together. Now the user clusters are: $\left\{\left\{u_{4}\right\},\left\{u_{1}, u_{2}, u_{3}, u_{5}\right\}\right\}$. The result shows that web user $u_{1}$ is the firm relation user and the related correlative degree of $\mathrm{u}_{1}, \mathrm{u}_{2}, \mathrm{u}_{3}$ and $\mathrm{u}_{5}$ is 0.76 .

When the values are $0.74,0.66$ and 0.62 there will be no significant change in the clusters as it corresponds to the users' $\mathrm{u}_{1}, \mathrm{u}_{2}$ and $\mathrm{u}_{3}$ which are already included in the above cluster.

When the value is 0.54 , it corresponds to the users' $u_{4}$ and $u_{5}$. Hence cluster $u_{4}$ and $u_{5}$ together. Since $u_{5}$ is already in a cluster with $\mathrm{u}_{1}, \mathrm{u}_{2}$ and $\mathrm{u}_{3}$, cluster $\mathrm{u}_{1}, \mathrm{u}_{2}, \mathrm{u}_{3}, \mathrm{u}_{4}$ and $\mathrm{u}_{5}$ together. Now the single user cluster is: $\left\{\left\{\mathrm{u}_{1}, \mathrm{u}_{2}, \mathrm{u}_{3}, \mathrm{u}_{4}, \mathrm{u}_{5}\right\}\right\}$. The result shows that web user $u_{4}$ is the infirm relation user and the related correlative degree of all the users is 0.54 .

Now stop clustering as all the users are in a single cluster. 


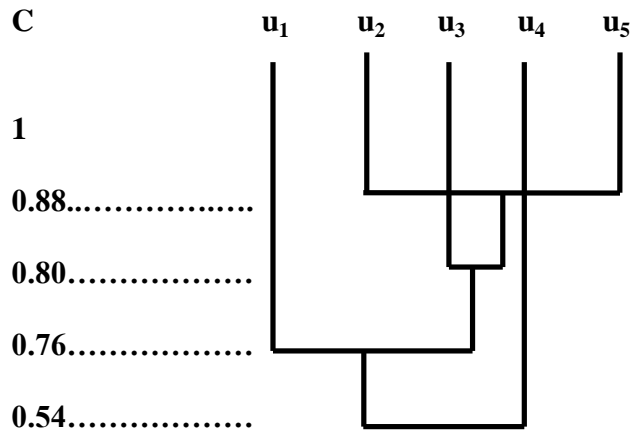

Fig 3: Resultant Graph2 of the user clusters

\subsection{Web Page Clustering}

\subsubsection{Relative Interestingness Degree of Web Pages}

From the pre-processed data the total number of times each web page accessed by each user; $\mathrm{pu}_{\mathrm{ij}}$ where $(i=1, \ldots, 9 ; \mathrm{j}=$ $1, \ldots, 5)$ is got. From Table $3, \mathrm{R}$ and $\mathrm{R}$ ' are obtained and the factor $\mathrm{c}$ in the demarcation step is set to 0.01 .

$$
\mathrm{r}_{\mathrm{ij}}=1-0.01 \sum_{k=1}^{m}\left|\mathrm{x}_{\mathrm{ik}}-\mathrm{x}_{\mathrm{jk}}\right|
$$

Table 3. Source Data

\begin{tabular}{|c|c|c|c|c|c|}
\hline & $\mathbf{u 1}$ & $\mathbf{u 2}$ & $\mathbf{u 3}$ & $\mathbf{u 4}$ & $\mathbf{u 5}$ \\
\hline $\mathbf{p 1}$ & 32 & 15 & 11 & 18 & 17 \\
\hline $\mathbf{p 2}$ & 23 & 28 & 21 & 21 & 27 \\
\hline $\mathbf{p 3}$ & 9 & 23 & 19 & 18 & 24 \\
\hline $\mathbf{p 4}$ & 15 & 23 & 11 & 9 & 10 \\
\hline $\mathbf{p 5}$ & 14 & 21 & 18 & 17 & 16 \\
\hline $\mathbf{p 6}$ & 26 & 23 & 12 & 23 & 34 \\
\hline $\mathbf{p 7}$ & 10 & 25 & 30 & 18 & 14 \\
\hline $\mathbf{p 8}$ & 18 & 34 & 24 & 15 & 16 \\
\hline $\mathbf{p 9}$ & 21 & 30 & 18 & 14 & 23 \\
\hline
\end{tabular}

$$
R=\left[\begin{array}{lllll}
32 & 15 & 11 & 18 & 17 \\
23 & 28 & 21 & 21 & 27 \\
09 & 23 & 19 & 18 & 24 \\
15 & 23 & 19 & 18 & 24 \\
14 & 21 & 18 & 17 & 16 \\
26 & 23 & 12 & 23 & 34 \\
10 & 25 & 30 & 18 & 14 \\
18 & 34 & 24 & 15 & 16 \\
21 & 30 & 18 & 14 & 23
\end{array}\right]
$$

$$
R^{\prime}=\left[\begin{array}{lllllllll}
1.00 & 0.55 & 0.54 & 0.59 & 0.67 & 0.63 & 0.46 & 0.50 & 0.57 \\
0.55 & 1.00 & 0.73 & 0.48 & 0.66 & 0.74 & 0.59 & 0.69 & 0.82 \\
0.54 & 0.73 & 1.00 & 0.63 & 0.83 & 0.61 & 0.76 & 0.64 & 0.75 \\
0.59 & 0.48 & 0.63 & 1.00 & 0.76 & 0.50 & 0.61 & 0.61 & 0.62 \\
0.67 & 0.66 & 0.83 & 0.76 & 1.00 & 0.56 & 0.77 & 0.75 & 0.74 \\
0.63 & 0.74 & 0.61 & 0.50 & 0.56 & 1.00 & 0.39 & 0.43 & 0.62 \\
0.46 & 0.59 & 0.76 & 0.61 & 0.77 & 0.39 & 1.00 & 0.72 & 0.59 \\
0.50 & 0.69 & 0.64 & 0.61 & 0.75 & 0.43 & 0.72 & 1.00 & 0.79 \\
0.57 & 0.82 & 0.75 & 0.62 & 0.74 & 0.62 & 0.59 & 0.79 & 1.00
\end{array}\right]
$$

After this apply clustering step to get the web page clusters based on the relative interesting degree of the web pages. Form the descending degree of the values in the web fuzzy matrix. The values are: $1>0.83>0.82>0.79>0.77>0.76>$ $0.75>0.74>0.73>0.72>0.69>0.67$.
When the value is 1 the web pages set $P$ is clustered into nine clusters: $\left.\left\{\mathrm{p}_{1}\right\},\left\{\mathrm{p}_{2}\right\},\left\{\mathrm{p}_{3}\right\},\left\{\mathrm{p}_{4}\right\},\left\{\mathrm{p}_{5}\right\},\left\{\mathrm{p}_{6}\right\},\left\{\mathrm{p}_{7}\right\},\left\{\mathrm{p}_{8}\right\},\left\{\mathrm{p}_{9}\right\}\right\}$. The result has no distinct meaning here.

When the value is 0.83 , it corresponds to the pages $p_{3}$ and $p_{5}$. Hence cluster $p_{3}$ and $p_{5}$ together. Now the page clusters are: $\left\{\left\{p_{1}\right\},\left\{p_{2}\right\},\left\{p_{3}, p_{5}\right\},\left\{p_{4}\right\},\left\{p_{6}\right\},\left\{p_{7}\right\},\left\{p_{8}\right\},\left\{p_{9}\right\}\right\}$. The result shows that web pages' $p_{3}$ and $p_{5}$ are the most interesting pages and their related active degree is 0.83 .

When the value is 0.82 , it corresponds to the pages $p_{2}$ and $p_{9}$. Hence cluster $p_{2}$ and $p_{9}$ together. Now the page clusters are: $\left\{\left\{p_{1}\right\},\left\{p_{2}, p_{9}\right\},\left\{p_{3}, p_{5}\right\},\left\{p_{4}\right\},\left\{p_{6}\right\},\left\{p_{7}\right\},\left\{p_{8}\right\}\right\}$. The result shows that web pages' $p_{2}$ and $p_{9}$ are the most interesting pages and their related active degree is 0.82 .

When the value is 0.79 , it corresponds to the pages $p_{8}$ and $p_{9}$. Hence cluster $\mathrm{p}_{8}$ and $\mathrm{p}_{9}$ together. Since $\mathrm{p}_{9}$ is already in a cluster with $\mathrm{p}_{2}$, cluster $\mathrm{p}_{2}, \mathrm{p}_{8}$ and $\mathrm{p}_{9}$ together. Now the page clusters are: $\left\{\left\{\mathrm{p}_{1}\right\},\left\{\mathrm{p}_{2}, \mathrm{p}_{8}, \mathrm{p}_{9}\right\},\left\{\mathrm{p}_{3}, \mathrm{p}_{5}\right\},\left\{\mathrm{p}_{4}\right\},\left\{\mathrm{p}_{6}\right\},\left\{\mathrm{p}_{7}\right\}\right\}$. The result shows that web page $\mathrm{p}_{8}$ is the more interesting page and the related active degree of $\mathrm{p}_{2}, \mathrm{p}_{8}$ and $\mathrm{p}_{9}$ is 0.79 .

When the value is 0.77 , it corresponds to the pages $p_{5}$ and $p_{7}$. Hence cluster $p_{5}$ and $p_{7}$ together. Since $p_{5}$ is already in a cluster with $p_{3}$, cluster $p_{3}, p_{5}$ and $p_{7}$ together. Now the page clusters are: $\left\{\left\{\mathrm{p}_{1}\right\},\left\{\mathrm{p}_{2}, \mathrm{p}_{8}, \mathrm{p}_{9}\right\},\left\{\mathrm{p}_{3}, \mathrm{p}_{5}, \mathrm{p}_{7}\right\},\left\{\mathrm{p}_{4}\right\},\left\{\mathrm{p}_{6}\right\}\right\}$. The result shows that web page $p_{7}$ is the more interesting page and the related active degree of $p_{3}, p_{5}$ and $p_{7}$ is 0.77 .

When the value is 0.76 , it corresponds to the pages $\mathrm{p}_{4}$ and $\mathrm{p}_{5}$. Hence cluster $p_{4}$ and $p_{5}$ together. Since $p_{5}$ is already in a cluster with $\mathrm{p}_{3}$ and $\mathrm{p}_{7}$ cluster $\mathrm{p}_{3}, \mathrm{p}_{4}, \mathrm{p}_{5}$ and $\mathrm{p}_{7}$ together. Now the page clusters are: $\left\{\left\{p_{1}\right\},\left\{p_{2}, p_{8}, p_{9}\right\},\left\{p_{3}, p_{4}, p_{5}, p_{7}\right\}\right.$, $\left.\left\{p_{6}\right\}\right\}$. The result shows that web page $p_{4}$ is the interesting page and the related active degree of $\mathrm{p}_{3}, \mathrm{p}_{4}, \mathrm{p}_{5}$ and $\mathrm{p}_{7}$ is 0.76 .

When the value is 0.75 , it corresponds to the pages $p_{3}$ and $p_{9}$. Hence cluster $p_{3}$ and $p_{9}$ together. Since $p_{3}$ is already in a cluster with $\mathrm{p}_{4}, \mathrm{p}_{5}$ and $\mathrm{p}_{7}$, and $\mathrm{p}_{9}$ is already in cluster with $\mathrm{p}_{2}$ and $\mathrm{p}_{8}$, cluster $\mathrm{p}_{2}, \mathrm{p}_{3}, \mathrm{p}_{4}, \mathrm{p}_{5}, \mathrm{p}_{7}, \mathrm{p}_{8}$ and $\mathrm{p}_{9}$ together. Now the page clusters are: $\left\{\left\{\mathrm{p}_{1}\right\},\left\{\mathrm{p}_{2}, \mathrm{p}_{3}, \mathrm{p}_{4}, \mathrm{p}_{5}, \mathrm{p}_{7}, \mathrm{p}_{8}, \mathrm{p}_{9}\right\},\left\{\mathrm{p}_{6}\right\}\right\}$. The result shows that web pages $p_{3}$ and $p_{9}$ are the interesting pages and the related active degree of $\mathrm{p}_{2}, \mathrm{p}_{3}, \mathrm{p}_{4}, \mathrm{p}_{5}, \mathrm{p}_{7}, \mathrm{p}_{8}$ and $\mathrm{p}_{9}$ is 0.75 .

When the value is 0.74 , it corresponds to the pages $\mathrm{p}_{2}$ and $\mathrm{p}_{6}$. Hence cluster $p_{2}$ and $p_{6}$ together. Since $p_{2}$ is already in a cluster with $\mathrm{p}_{3}, \mathrm{p}_{4}, \mathrm{p}_{5}, \mathrm{p}_{7}, \mathrm{p}_{8}$ and $\mathrm{p}_{9}$, cluster $\mathrm{p}_{2}, \mathrm{p}_{3}, \mathrm{p}_{4}, \mathrm{p}_{5}, \mathrm{p}_{6}, \mathrm{p}_{7}$, $\mathrm{p}_{8}$ and $\mathrm{p}_{9}$ together. Now the page clusters are: $\left\{\left\{\mathrm{p}_{1}\right\},\left\{\mathrm{p}_{2}, \mathrm{p}_{3}\right.\right.$, $\left.\left.\mathrm{p}_{4}, \mathrm{p}_{5}, \mathrm{p}_{6}, \mathrm{p}_{7}, \mathrm{p}_{8}, \mathrm{p}_{9}\right\}\right\}$. The result shows that web page $\mathrm{p}_{6}$ is the uninteresting page and the related active degree of $\mathrm{p}_{2}, \mathrm{p}_{3}, \mathrm{p}_{4}$, $\mathrm{p}_{5}, \mathrm{p}_{6}, \mathrm{p}_{7}, \mathrm{p}_{8}$ and $\mathrm{p}_{9}$ is 0.74 .

When the values are $0.73,0.72$ and 0.69 there will be no significant change in the clusters as it corresponds to the pages $\mathrm{p}_{2}, \mathrm{p}_{3}, \mathrm{p}_{7}$ and $\mathrm{p}_{8}$ which are already included in the above cluster.

When the value is 0.67 , it corresponds to the pages $p_{1}$ and $p_{5}$. Hence cluster $p_{1}$ and $p_{5}$ together. Since $p_{5}$ is already in a cluster with $\mathrm{p}_{2}, \mathrm{p}_{3}, \mathrm{p}_{4}, \mathrm{p}_{6}, \mathrm{p}_{7}, \mathrm{p}_{8}$ and $\mathrm{p}_{9}$, cluster $\mathrm{p}_{1}, \mathrm{p}_{2}, \mathrm{p}_{3}, \mathrm{p}_{4}, \mathrm{p}_{5}$, $p_{6}, p_{7}, p_{8}$ and $p_{9}$ together. Now the single page cluster is: $\left\{\left\{p_{1}\right.\right.$, $\left.\left.\mathrm{p}_{2}, \mathrm{p}_{3}, \mathrm{p}_{4}, \mathrm{p}_{5}, \mathrm{p}_{6}, \mathrm{p}_{7}, \mathrm{p}_{8}, \mathrm{p}_{9}\right\}\right\}$. The result shows that web page $\mathrm{p}_{1}$ is the uninteresting page and the related active degree of $\mathrm{p}_{1}$, $\mathrm{p}_{2}, \mathrm{p}_{3}, \mathrm{p}_{4}, \mathrm{p}_{5}, \mathrm{p}_{6}, \mathrm{p}_{7}, \mathrm{p}_{8}$ and $\mathrm{p}_{9}$ is 0.67 .

Now stop clustering as all the pages are in a single cluster. 


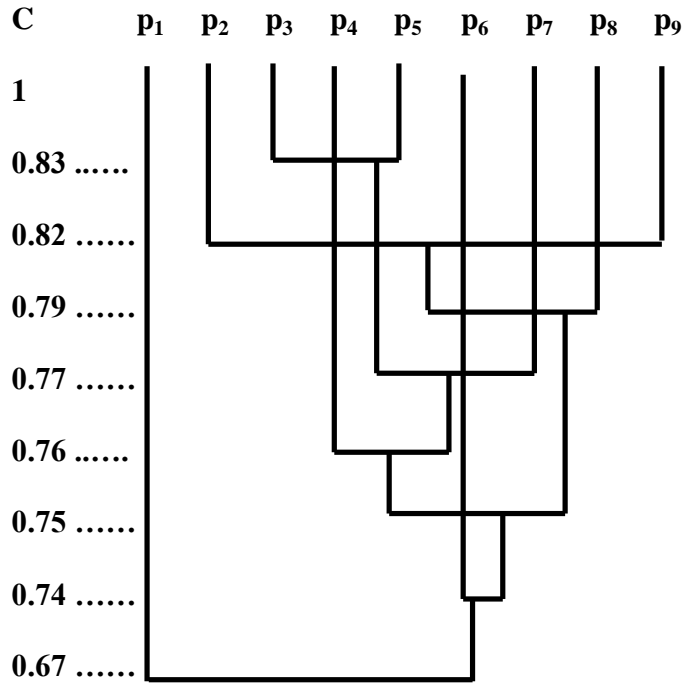

Fig 4: Resultant Graph1 of the page clusters

\subsubsection{Correlative Degree of Web Pages}

This step can be deduced by analogy as in the previous steps.

\section{CONCLUSION}

In this paper, the concept and processing model of Matrix Based Fuzzy Clustering Approach MBFCA is put forward and discussed. The experimental results are shown to prove that this approach can be used for effective web user clustering and web page clustering. This is a simple to implement approach. This approach will produce efficient clusters of web users and web pages with less run time and with reduced memory usage. The resultant web page and web user clusters are found to match the existing web page and web user clusters in the given sample data. One future work on this could be to create matrices that reflect the time each user spends on each page and come up with a different set of web user and web page clusters based on this data. Another future scope for this approach is that this can be automated using any programming language and can be used to measure the efficiency of this approach for many web sites.

\section{REFERENCES}

[1] Jiawei Han and Micheline Kamber, Data Mining Concepts and Techniques, 2nd ed., China Machine Press, Beijing, China, 2007.

[2] Han, Q., Gao, X., Wu, W.: Study on Web Mining Algorithm Based on Usage Mining. In: 9th International Conference on Computer-Aided Industrial Design and Conceptual Design, CAID/CD November 2008.

[3] Ying-Gui Li and Gui-Ji LI, Web Log Mining Based On Fuzzy Clustering, Computer Science, China, 2004, 31(12):97-100.

[4] Jing-Gong Li and Xiang-Gong WangS. Zhang, Fuzzy Set Theory And Application, Chain Science Press, Beijing, China, 2004.

[5] M. J. Martin-Bautista, D. H. Kraft, M. A. Vila, J. Chen and J. Cruz, "User profiles and fuzzy logic for Web retrieval issues," in Soft Computing Journal, 2004, vol. 6, number 5, pp. 365-372.
[6] D. Arotaritei and S. Mitra, "Web Mining: a survey in the fuzzy framework," in Fuzzy Sets and System, 2000, vol. 148, pp. 5-19.

[7] Facca, F. M., \& Lanzi, P. L. (2005). Mining Interesting Knowledge from Weblogs: A Survey, 53, 225-241.

[8] RENATA IVANCSY and FERENC KOVACS, "Clustering Techniques Utilized in Web Usage Mining," in Proceedings of the $5^{\text {th }}$ WSEAS Int. Conf. on Artificial Inlelligence, Knowledge Engineering and Data Bases, Madrid, Spain, February 15-17, 2006, pp. 237-242.

[9] S. Araya, M. Silva and R. Weber, "A methodology for web usage mining and its application to target group identification," in Fuzzy Sets and Systems, 2004, vol. 148 , pp. 139-152.

[10] Sudhamathy, G. 2010. Mining web logs: an automated approach. In Proceedings of the 1st Amrita ACM-W Celebration on Women in Computing in india (Coimbatore, India, September 16 - 17, 2010). A2CWiC '10. ACM, New York, NY, 1-4. DOI= http://doi.acm.org/10.1145/1858378.1858435

[11] Mobasher, B., Cooley, R., Srivastava, J.: Automatic Personalization Based on Web Usage Mining (2000), http://maya.cs.depaul.edu/ mobasher/personalization/

[12] J. Srivastava, R. Cooley, M. Deshpande and P. N. Tan, "Web usage mining: discovery and applications of usage patterns from web data," SIGKDD Explorations, 2000, vol. 1 , number 2 , pp. 12-23.

[13] A. Vakali, J. Pokorný and T. Dalamagas, "An Overview of Web Data Clustering Practices," EDBT Workshops, 2004, pp. 597-606.

[14] Xinlin Zhang, Xiangdong Yin "Design of an Information Intelligent System based on Web Data Mining", IEEE International Conference on Computer Science and Information Technology, 2008, p. 88-91.

[15] Chu-Hui Lee, Yu-Hsiang Fu "Web Usage Mining Based on Clustering of Browsing Features", IEEE Eighth International Conference on Intelligent Systems Design and Applications, 2008, p. 281-286.

[16] Thorleuchter, D., Poel, D. V. D., \& Prinzie, A. (2012). Analyzing existing customers' websites to improve the customer acquisition process as well as the profitability prediction in B-to-B marketing. Expert Systems with Applications, 39, 2597-2605. 